\title{
Crossflex: Concept and early development of a true building integrated wind turbine
}

\author{
Tim Sharpe ${ }^{\mathrm{a}, *}$, Gordon Proven ${ }^{\mathrm{b}}$ \\ a Mackintosh Environmental Architecture Research Unit (MEARU), Glasgow School of Art, Glasgow, G3 6RQ Scotland, UK \\ ${ }^{b}$ Proven Energy Ltd. Wardhead Park, Stewarton, Ayrshire, KA3 5LH, Scotland, UK
}

\section{A R T I C L E I N F O}

\section{Article history:}

Received 4 March 2010

Received in revised form 22 June 2010

Accepted 28 July 2010

\section{Keywords:}

Architecture

Buildings

Energy

Renewables

Small wind

Turbine

Urban

Integration

Housing

\begin{abstract}
A B S T R A C T
This paper describes the concept development and work to date, of an innovative 'true' building integrated wind turbine. The context for this is the role of small-scale renewable energy in addressing climate change. In the UK a number of small wind turbines have reached the market, however, in almost all cases, these are existing HAWT or VAWT tower mounted systems. Due to their inherent design qualities, and issues such as planning requirements, these have much reduced output due to their form and siting and are unable to take advantage of augmented airflow around buildings.

The Crossflex proposal is a radical new development of a Darrieus turbine form. As well as having a technically innovative flexible blade system, it also utilises a lightweight cowling system that can provide both augmented airflow and improved visual integration into new and existing building forms. It is a modular form that can be sited on ridges and corners of buildings to provide useful levels of generation.
\end{abstract}

(c) 2010 Elsevier B.V. All rights reserved.

\section{Introduction}

The increasing threats of climate change, along with diminishing fossil fuel energy sources, and uncertainly over security of energy supplies, underscore the increasing value of renewable energy. The UK Government has set some challenging targets to meet its obligations under the Kyoto climate change protocol. Both the UK The Climate Change Act [1] and the Scotland Government Climate Change (Scotland) Act 2009 requires an $80 \%$ reduction by 2050 [2].

The role of the built environment is crucial to these objectives. Buildings account for about $50 \%$ the UK energy consumption, and housing produces $27 \%$ of $\mathrm{CO}_{2}$ emissions [3]. European legislation now requires energy performance certificates and the 2008 budget announced a target for all new housing to be carbon neutral by 2016, with all new buildings carbon neutral by 2019.

Much of this legislation is directed at new buildings, however, these represent only $1.5 \%$ of the UK building stock year. The Carbon Trust has identified that $60 \%$ of the buildings due to be standing in 2050 already exist and, even more importantly, nearly half of these buildings will have been built before 1985 when Part L was first introduced [4]. Consequently, both new and perhaps

\footnotetext{
* Corresponding author. Tel.: +44 0141353 4740; fax: +44 01413534740 .

E-mail address: t.sharpe@gsa.ac.uk (T. Sharpe).
}

more importantly, existing buildings, will need to reflect these standards.

Whilst a substantial proportion of these targets may be met through reduction in demand and large-scale energy generation, there is increasing interest in distributed (also known as embedded and micro) energy generation, produced on or by buildings, through a range of technologies such as photovoltaics, combined heat and power, and wind.

As distributed generators are mostly those generating power from renewable energy sources, they are extremely well placed to help achieve Government targets [5]. Several reports such as the DTI Micro-generation strategy [6] and the Scottish Executive Energy Efficiency and Micro-Generation Bill proposal [7] have highlighted the potential benefits of this approach and provided government support through the Energy Savings Trust and Carbon Trust funding schemes.

Planning authorities are also required include policies in their development plans that require a percentage of the energy in new developments to come from on-site renewables [9].

Furthermore the introduction of Feed In Tariffs (FIT) in 2011 will provide further incentives for adoption of low energy strategies [8].

Although the political will has been established, the means by which these targets can be achieved is less evident. Because of the these recent shifts, in part triggered by policies such as the Merton rule (www.themertonrule.org), but also ambitions on the part of some designers and clients and stimulation from grant 
aid (www.energysavingtrust.org.uk) there have been an increasing number of attempts to use building integrated renewables, including wind turbines.

The difference between installations on existing or new buildings is also important. In considering the most effective use of resources, for new buildings the most efficient strategy is to use insulation and low energy devices to reduce demand and as a consequence, the need for energy is small. However, the situation changes when considering existing buildings. Much of this stock has poor performance, and opportunities for reduction in demand are far more limited. It is this sector therefore which can derive the greatest benefit from renewables and devices should be available for this sector.

There have been major advances in the technology and efficiency of large-scale wind installations, but the use of small turbines in urban areas is a relatively under researched area. Previous work by Mertens has identified that there are possible benefits from the theoretical augmentation of wind flow around buildings $[10,11]$, and this research has been developed in relation to building forms [12-15] and the use of ducted wind systems on buildings [16,17].

However, the majority of actual installations in urban contexts have been made using conventional HAWT, with some use of VAWT systems. These have generally been mast-mounted devices, which are designed for open sites. Difficulties have been encountered when placing these in urban contexts in relation to both predicted and actual performance. Despite attempts to improve this by tools such as $\mu$-wind [5], subsequent research has shown that performance remains highly site-specific [18].

Although there is a clear potential, recent work indicates that there is increasing evidence that mounting turbines on to or near buildings has been detrimental to performance [19] resulting in relatively poor cost-effectiveness [20].

The other issue that has arisen is that of appearance and integration. In considering the use and performance of current turbines technologies on buildings, the importance of appearance should not be underestimated in this market. Although current planning advice notes such as the Planning Policy Statement 22 have eased the situation the visual form and resultant placement of turbines remains problematical, with planning requirements to minimise visual impact at odds with technical requirements to have maximum exposure of the turbine. An example of this is that statutory planning consents may not be required if the turbine is below the roofline.

Several commercially available turbines have been marketed for the built environment as evidenced in their product literature, for example, Swift - "the first quiet rooftop wind turbine" [21]. This promotion has primarily been through their aesthetic performance, rather than any direct benefit of being building mounted. Some VAWT turbines have also been used in urban environments, such the Quiet Revolution produced by $\mathrm{XCO}_{2}$ "designed in response to increasing demand for wind turbines that work well in the urban environment" [22]; and Turby "especially designed for use in the built-up environment (urban areas) on the rooftop of high buildings" [23]. VAWT turbines have the advantage they do not need to rotate to face wind direction, and are visually more suited to be building mounted, but in general are not as efficient as HAWT installations. The fact that the popularity of some turbine forms is not based solely on their generating capacity illustrates the value placed on the appearance of devices that will be visible to the public. Whilst attractive appearance may be a useful driver to adoption of this technology, there is some inherent risk in this if the rationale of consumers becomes more to do with a public profile, rather than a realistic assessment of energy production. The term 'eco-bling' has been used to describe ostensible, but ineffectual devices. Nev- ertheless, if systems are productive, then carbon reductions will be achieved.

Concerns have also been raised about the longevity and safety of turbines within the urban environment and possible consequences of failure. One of the advantages of use of conventional turbine forms is their track record of reliability and robustness, but this then mitigates against the use of novel devices, especially when used in areas of complex airflow.

The additional cost of installation is also proving to be a significant barrier to building mounted systems [24]. Most systems require a bespoke adaption to a generic ground fixing system and this requires additional design and fabrication as well as statutory permissions such as building warrant. Furthermore, the costs of installation and later maintenance, for example crane hire, road closure and costs associated with working at height, particularly on high or exposed parts of buildings, compromise their costeffectiveness.

Although it can be demonstrated that there are economies of scale that can improve pay-back, the most effective technique use of larger turbines - is not visually or technically feasible on buildings. There are four reasons for this.

1 Large turbines would generate significant loads on the host building. These are generally not problems of the lateral stability of the building itself, but more localised loads onto the connection points.

2 The ability to access the turbine for maintenance or repair would be difficult and expensive.

3 Potential environmental factors such as noise and vibration may become more apparent, especially when the generator becomes large enough to require a gearing mechanism.

4 The relationship of the size of the turbine to the building itself. Although larger buildings could accommodate larger turbines, the overall proportion would limit what was visually acceptable.

In summary, whilst there are policy and economic drivers leading to an increasing demand for urban turbines, the current state of the art has not produced an effective building integrated turbine. At present it seems unlikely that a solution will emerge from a conventional HAWT, which in general are designed for mast mounting in unobstructed areas. In considering the shortfalls of existing systems, the following desirable characteristics emerge:

- Building integrated for visual performance.

- Building integrated for augmented flow.

- Scalable and economic through modularity.

- Good power output in turbulent and gusting sites.

- Ease of installation.

- Applicable in a wide variety of locations.

The Crossflex turbine concept was developed specifically in response to demands for turbines in urban situations. The work, initially funded by a SMART award is still in developmental stages. This paper is intended to provide an outline of the concept, and its potential impact in the built environment, and the following sections describe its general technical characteristics, and its potential for building integration.

\section{Turbine design}

Crossflex takes an existing concept, but uses it in a novel form. Georges Jeans Mary Darrieus invented the Darrieus turbine in 1931. It consists of two or more flexible aerofoil blades, which are attached to both the top and the bottom of a vertical rotating vertical shaft. The wind blowing over the aerofoil contours of the blade 


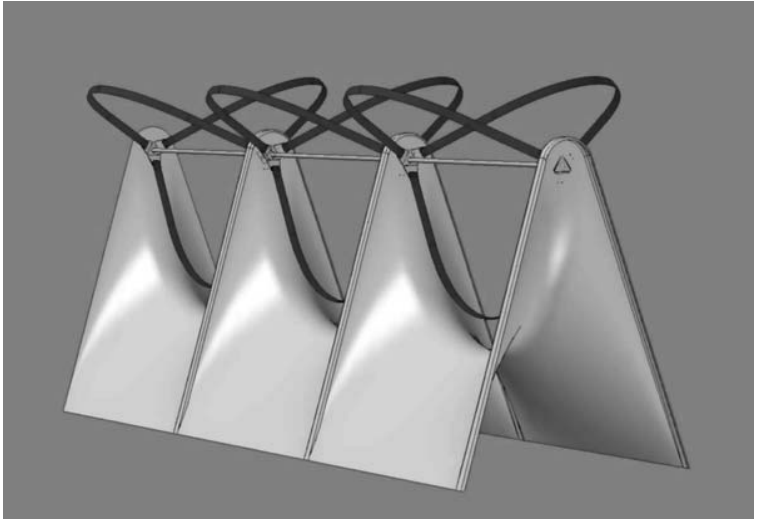

Fig. 1. Crossflex concept image.

creates aerodynamic lift, which provides a forward driving force to each of the blades thus generating mechanical power (Fig. 1).

Previous attempts to develop a large-scale commercial form have not generally been successful due to limitations of the design. In comparison to HAWT turbines, they have a rather low efficiency and have been unable to compete economically with megawattsized developments. In larger machines the length of the blades can lead to problems of vibration and noise at certain rotational speeds. As the blades move at higher speeds than the ambient wind, they can experience excessive speeds in high winds, and braking systems are required to control this. They have a high torque at low speeds, and therefore are not self-starting. In their conventional VAWT form they produce large loads on the shaft and bearings and there is a large cantilever action on the mounting.

The Crossflex turbine incorporates several innovative aspects to address these problems. The principle concept is to take the Darrieus form, but mount it within a frame with the shaft held at both ends so it can conceivably operate with the axis of rotation aligned either vertically or horizontally. This also reduces the loads on the bearings and shafts. The turbine is then held within a rigid cowling that enables it to be mounted on supporting building structures.

The principal innovations are:

- It maximises efficiency by incorporating a low solidity and low inertial mass design for the turbine blades.

- It minimises the bending stress in the blades via the use of flexible blades, which act as a "skipping rope" and rapidly assume their natural troposkien shape at rated speed.

- Limitation of the rotational speed of the turbine in high wind conditions can utilise a mechanism at the blade root(s), which induces a twisting of the blades out of optimum lift conditions, incorporating either stall or feathering conditions.

- The distribution loads results in low loading imposed on structure mountings and reduced vibration compared to both small-scale HAWT and previous Darrieus-type turbines.

- Absence of rotor blade tips produces significantly less noise with each revolution.

- It has the capability to extract energy from wind from any direction and additionally will cope with the turbulent flows which can occur around buildings

- Mounting within the cowling enables reduced loads on the shaft and bearings, potential augmented airflow over the blades, improved load distribution to supporting structures and better visual integration.

The research to date has examined a number of issues related to the theoretical performance, particularly those relating to the

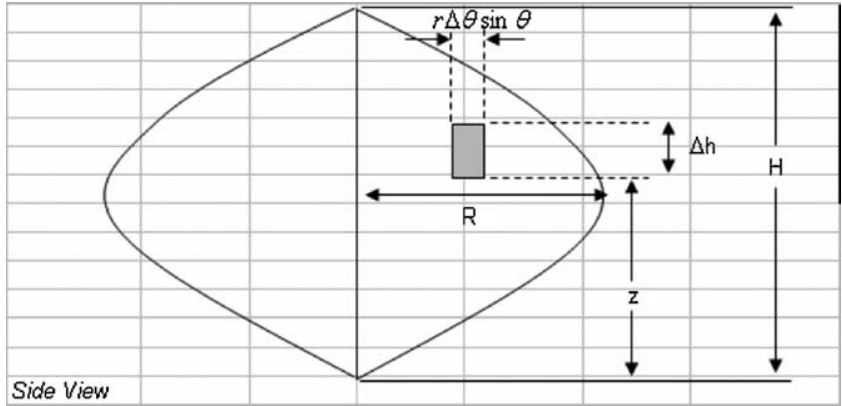

Fig. 2. Streamtube parameters.

blade design. Work has also been undertaken on the potential for building integration.

\subsection{Theoretical modelling}

In order to test the performance, analysis has been undertaken using a theoretical model developed from the multiple streamtube momentum balance approach first developed by Strickland [25] and later improved by Paraschivoiu [26].

The streamtube model describes most of the characteristics of the Darrieus turbine in operation but cannot account for more empirical phenomena such as dynamic stall, blade vortex interaction and so further work will be undertaken in laboratory scale testing. Modifications made to the model were the inclusion of downwind loss factor of 0.8 on the velocity profile available to the blades when operating in the downwind region, and pitch angle was introduced allowing user to specify a toe-in or toe-out angle.

At this stage the critical design issues include the variable twist aerofoil sections, the pitch control mechanism, aeroelastic stability issues and noise and vibration control (Fig. 3). These have been examined for more specific purposes such as analysing self-starting capabilities, assessing toe-in/toe-out angles, factoring for downwind losses and crucially, investigating the potential for passive over-speed control via blade pitch control (Fig. 2).

\subsection{Methods and procedure}

The streamtube method takes equal length sections of the blade along the rotor axis and carries out a momentum balance.

The model interprets the troposkien shape of the blade as nondimensionalised vertical and horizontal displacement variables. The values of angle of attack, $\alpha$, and relative wind velocity, $W$, are calculated from the meridional angle, the free-stream wind speed, the azimuth angle and the rotor rpm through Eq. (1).

$\alpha=\tan ^{-1}\left(\frac{V \sin \theta \sin \delta}{V \cos \theta+r \omega}\right)$ and $W \sin \alpha=V \sin \theta \sin \delta$

The model takes the $C_{\mathrm{l}}$ (Coefficient of Lift) and $C_{\mathrm{d}}$ (Coefficient of Drag) data at a certain Reynold's number and calculates both the tangential and the normal coefficients of thrust for each section of the blade based on the geometry of the troposkien shape for each value of $\alpha$ as it varies along the blade.

The next step is to use those values of normal coefficient of thrust $\left(C_{\mathrm{N}}\right)$ and tangential coefficient of thrust $\left(C_{\mathrm{T}}\right)$ together with the surface area of each blade segment in order to calculate the elemental torque $\left(T_{\mathrm{S}}\right)$ for each segment. The torque for one blade $\left(T_{\mathrm{B}}\right)$, is found simply by taking the sum of the elemental torques for all the elements comprising a blade.

This gives the instantaneous torque at a specific azimuth angle for one blade. By introducing a phase angle it was possible to simulate the equal separation of 3 identical blades and the effect this 
would have on the aggregate instantaneous rotor torque for one rotation. Since the coefficient of power $\left(C_{\mathrm{p}}\right)$ is calculated from the average rotor torque per rotation, a decision was made to take the aggregate instantaneous torque for all 3 blades and divide by the number of increments of azimuth angle, which number $37\left(0-360^{\circ}\right)$ in this case.

By using Eq. (2) below, a value for $C_{p}$ can be calculated and the process can be iterated as many times as desired to provide sufficient data to create a power curve.

$$
C_{\mathrm{p}}=\frac{\bar{T} \omega}{1 / 2 \rho \sum_{1}^{N_{\mathrm{S}}} 2 r \Delta h V_{\infty}^{3}}
$$

The streamtube model spreadsheet has a number of user interfaces, allowing every variable in the model to be changed; from aerofoil section, troposkien shape, blade chord, rotor height, rotor diameter.

In addition a number of Visual Basic ${ }^{\mathrm{TM}}$ macros were written to automate and streamline the calculations and iterations behind the method of the streamtube model. These are as follows:

- "Calculate torque" - This macro acts to change the value of azimuth angle $\theta$ until all values of elemental torque TS from $\theta=0-360^{\circ}$ have been calculated for.

- "Resultant streamwise force" - This macro calculates the loss of momentum through the streamtube which then iterates to find the velocity interference factor from the rotor. In addition to this, a downwind loss factor is imposed.

- "Calculate AA vs azimuth" - This calculates the variation in angle of attack with azimuth at the blade equator

- "Power Output" - Not a macro but calculates the rated power output using the $C_{\mathrm{p}}$ value at rated power.

\subsection{Reynold's number}

The blade Reynold's number (Re) is calculated through Eq. (3):

$R e=\frac{\rho U D}{v}$

where $\rho$ : density, $U$ : local velocity, $D$ : dimensional parameter $v$ : kinematic viscosity. Taking operating conditions as rated, the range of Reynold's number on each blade from Vcut-in to Vrated is from 60,000 at the blade ends/hub to 350,000 at the blade equator. A decision was made to take the values of $C_{1}$ and $C_{d}$ at 360,000, as this accurately describes the blades at their rated condition and provides a good overall idea of the turbine performance.

However, the Reynold's number could be important particular when considering start-up at lower apparent wind speeds. Therefore, in further analysis the $C_{1}, C_{d}$ data can be changed to the data corresponding to an appropriate Re, when start-up is being considered more in-depth. The difference in $C_{1}, C_{\mathrm{d}}$ values within this range of $R e$ is not significant enough to warrant recalculation at this stage.

Although the multiple streamtube model does not have an inbuilt facility to account for difference in upwind and downwind velocities, it was very easy to incorporate this by simply adding a loss factor to the induced velocities in the upwind region. This gave rise to a more realistic model, which truly represented the difference in magnitude between the upwind and downwind sections of the blade rotational envelope.

The following analysis has been based on a turbine with the following specifications: Rotor height $=2.73 \mathrm{~m}$, diameter $=2.436 \mathrm{~m}$, chord $=0.07 \mathrm{~m}$, blade length $=3.55 \mathrm{~m}$, blades $=3$, swept area $=4.44 \mathrm{~m}^{2}$ ). Detailed analysis is beyond the scope of this paper, but several key characteristics are emerging.

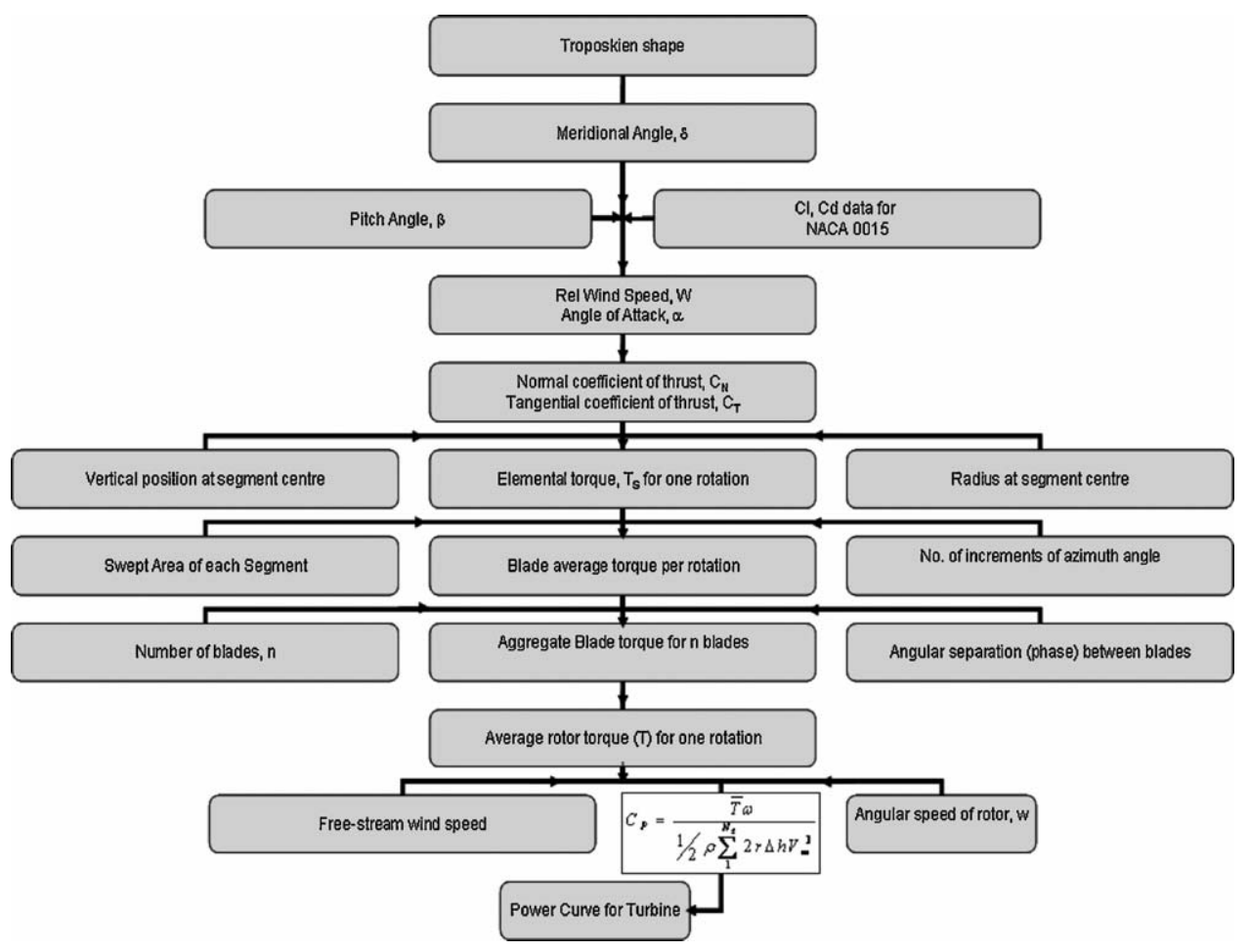

Fig. 3. Streamtube process flowchart. 


\section{Discussion}

\subsection{Blade design}

The blade design incorporates low solidity and low mass materials. These flexible blades rapidly assume their natural troposkein shape at speed. Several configurations of blade cross-section are under consideration. As very little bending is experienced, there is greater scope for use of anisotropic materials, or composites to provide the section shape, with various configurations of ropes or wires providing the principal tensile strength.

One of the principle advantages of the inherent flexibility is the ability to induce twisting in the blades. The ability to change the aerodynamic properties leads to the possibility of optimisation of performance in a number of areas including equalisation of torque forces, rotor speed control and over-speed limitation.

The intention is to utilise a twisting mechanism at the blade $\operatorname{root}(\mathrm{s})$, which deforms the blade across its length. Mechanisms to induce this twisting are still under development and may occur at one blade end, at both, or in the centre. Ideally the twisting mechanism will occur naturally through the centripetal tension in the blades, but it may need to be augmented by the use of motors or any other suitable control device. Where this is the case, the twisting will not be caused directly by the centripetal tension in the blades but will nonetheless be linked to this value. In other words the motor or control device will operate at the same critical rotational speed, determined perhaps instead by accelerometers.

The ability to use the properties of the blades to generate twisting enables several enhancements to performance and operation and these are discussed below.

\subsection{Pitch control}

One of the difficulties with this turbine type is the unequal distribution of torque forces on the upwind and downwind cycles. An analysis of the effects of blade angle on performance was undertaken using the streamtube model and this is shown in Fig. 4.

In the analysis this is addressed by imposing a negative pitch or "toe-out" angle to favour the downwind case. The aerodynamic effect of doing this is fairly simple and can be shown in Fig. 5.

On the upwind case, the effect of a negative pitch angle is to reduce the effective angle of attack on the aerofoil. In the downwind case the opposite is true, where the negative pitch angle acts to increase the new angle of attack due to the angle of attack already being negative in this region.

Examination of the case with a $0.5^{\circ}$ toe-out produces the following result shown in Fig. 6.

Clearly this now produces a more even peak torque distribution at rated rpm. However, this effect only applies at the rated

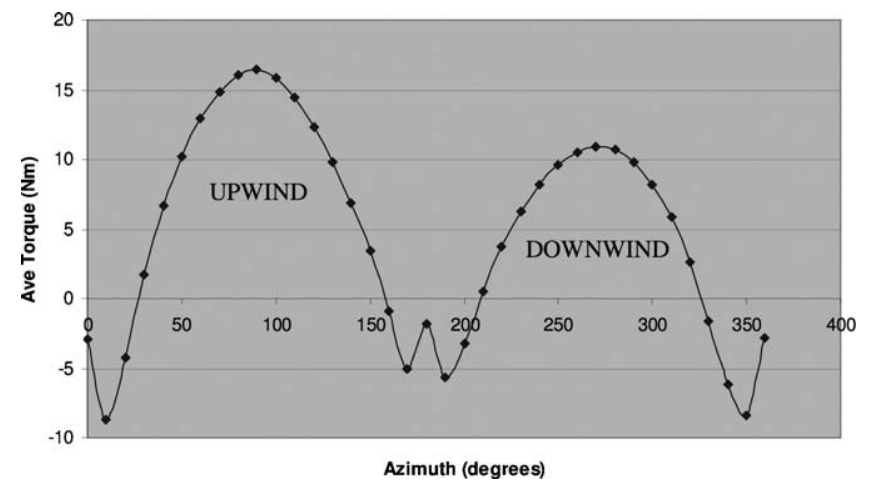

Fig. 4. Variation in blade 1 torque with azimuth angle.

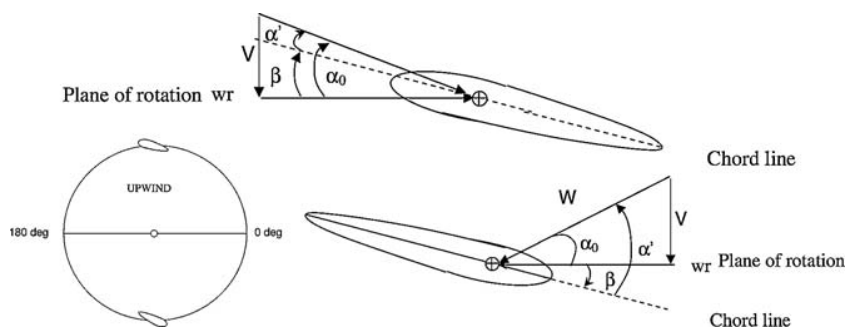

Fig. 5. Upwind and downwind toe angles.

wind speed, and the problem with imposing a constant toe-out angle which produces even torque peaks at rated wind speed is that above and below the rated wind speed, the uneven torque peak will appear again due to the different variations in angle of attack. In other words a toe-out angle of $-0.5^{\circ}$ will only favour conditions at rated wind speed $(10.5 \mathrm{~m} / \mathrm{s}$ in this case).

Examination of blade torque at higher and lower wind speeds indicates that the imbalance returns with increasing difference between rated wind speeds.

Whilst variations in pitch have little effect on the overall coefficient of performance and small toe-out angle to smoothen out the torque peaks of the upwind and downwind sections a constant pitch angle can never smooth out the torque peaks for the entire operational envelope.

With a fixed angle the optimum pitch would be generated from the following parameters:

- Even torque peaks at rated velocity,

- Even peak torques just before rated,

- Even peak torques at start-up, etc.

However, the inherent flexibility of the blades provides the possibility of a dynamic pitch angle, whereby the blade can be configured with a spring to gradually increase the magnitude of the negative pitch angle with increasing rpm (via centrifugal force). After experiment, the best pitch angles for even torque peak are shown in Fig. 7:

This shows a linear relationship between wind speed and pitch angle required for even torque peaks. This could allow the use of a linear spring in order to control the pitch angle.

\subsection{Pitch control of rotor rpm}

Having established the potential for using small toe-out angles to improve uneven torque, the next step was to assess the effectiveness of pitch control to limit the turbine rpm at high wind conditions or in case of generator failure. For an unloaded turbine or for an insufficiently loaded turbine in gust conditions, the power

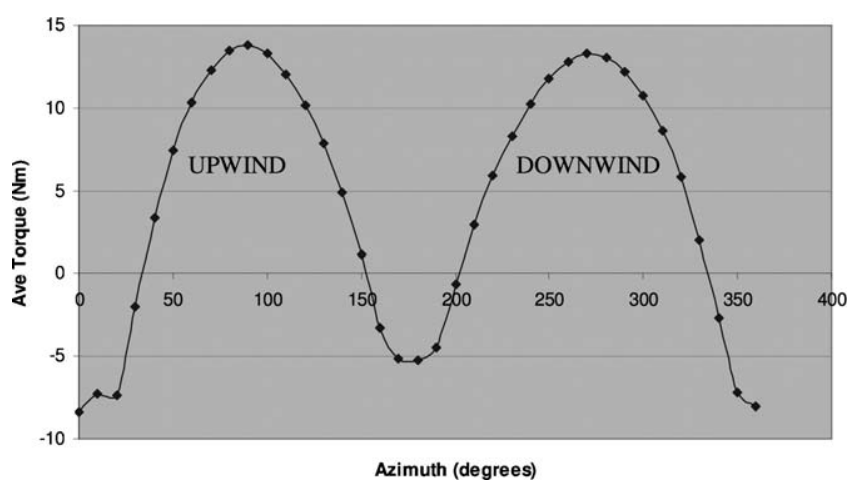

Fig. 6. Variation in blade 1 torque with azimuth angle at $10.5 \mathrm{~m} / \mathrm{s}$. 


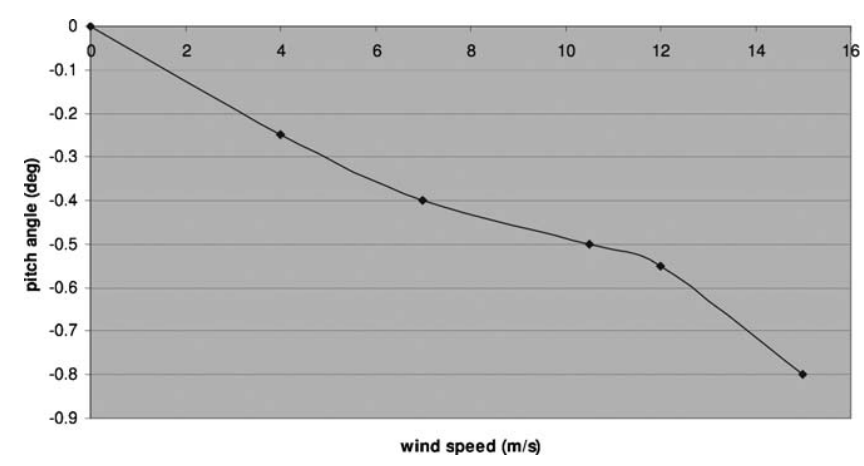

Fig. 7. Wind speed vs pitch angle for constant torque peak.

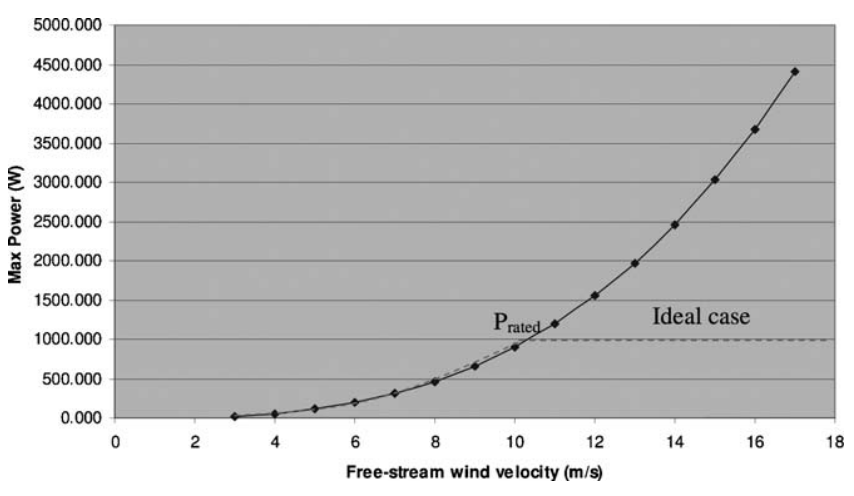

Fig. 8. Power curve.

produced by the turbine will increase exponentially with increasing wind speed as shown in Fig. 8 below.

Since the intention is to produce a turbine with a rated power, it is necessary to provide a means of over-speed limitation which inhibits further torque increase beyond the corresponding rated wind speed. This is indicated in red. Limiting the rotor rpm is also important when considering the generator coupled to the rotor shaft, as most generators operate most effectively within a fairly narrow ratio of maximum to minimum rpm (usually about 4-1).

Since the coefficient of power equation is simply the average torque per rotation divided by the dynamic power in the wind, it is clear that in order to limit the power output of the turbine, one must limit the average torque per rotation above the rated wind speed. Since the average torque will depend on the combination of both upwind and downwind halves of one rotation, an iterative process must be carried out to identify the best pitch angle to limit the speed sufficiently beyond this point.

Examining power curves with varying speeds as shown in Fig. 9 reveals that the shaft mechanical power $P_{\mathrm{m}}$ rises to a maximum for

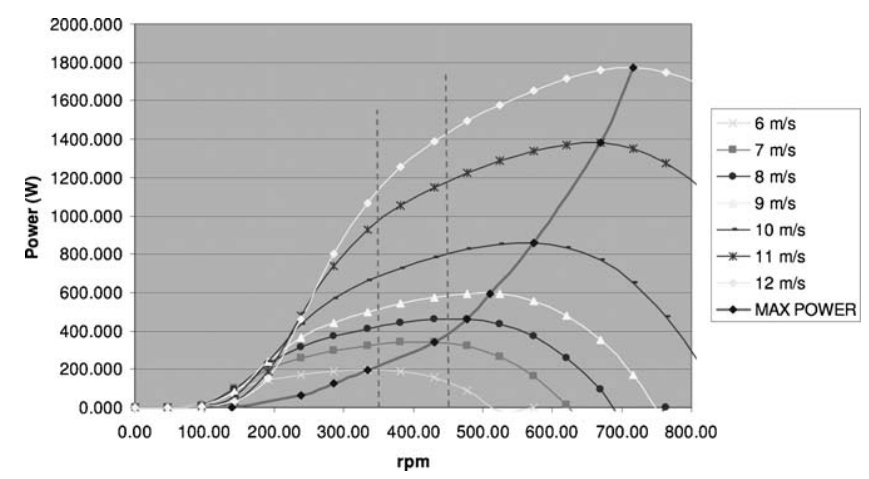

Fig. 9. Power curve with increasing wind speed. each wind speed for a particular value of rotational speed. Higher wind speeds have more power in the wind, and the change in tip speed ratio with increasing wind speed causes the maximum to shift to a higher rotational speed. Maximum power is reached at $334 \mathrm{rpm}$ in a $6 \mathrm{~m} / \mathrm{s}$ wind and at $716 \mathrm{rpm}$ in a $12 \mathrm{~m} / \mathrm{s}$ wind. The maximum possible shaft power in a $12 \mathrm{~m} / \mathrm{s}$ wind is approximately eight times that in a $6 \mathrm{~m} / \mathrm{s}$ wind, as would be expected from the cubic relationship with wind speed. At $350 \mathrm{rpm}$ we are close to the maximum shaft power for $V=6 \mathrm{~m} / \mathrm{s}$, but are below the maximum for higher wind speeds. In fact no additional power can be obtained from the wind above about $12 \mathrm{~m} / \mathrm{s}$ because curves for higher wind speeds follow the same line at this rotational speed. At $450 \mathrm{rpm}$ we are close to the maximum shaft power at $V=8 \mathrm{~m} / \mathrm{s}$, and are able to extract significantly more power from the wind for wind speeds above $8 \mathrm{~m} / \mathrm{s}$ than was possible at $350 \mathrm{rpm}$. It would appear that if fixed speed operation is required, then $450 \mathrm{rpm}$ is a good choice of operating rpm for sites with a high percentage of winds between 6 and $10 \mathrm{~m} / \mathrm{s}$ since the turbine can deliver nearly the maximum possible shaft power over this wind speed range. A higher fixed shaft speed would be justified only if there were a significant fraction of wind speeds above $10 \mathrm{~m} / \mathrm{s}$, which is unlikely in urban environments. Increasing the shaft speed above $450 \mathrm{rpm}$ would decrease the power for winds below $8 \mathrm{~m} / \mathrm{s}$, and so this would be a significant penalty at many sites especially considering the turbine start-up.

However, a further possibility for optimisation occurs when considering a variable speed rotor. Most wind turbines operate at fixed rotational speeds except when starting and stopping. This simplifies system operation when using synchronous generators paralleled with the utility grid. It also helps to prevent the turbine from being operated at a speed which will excite a mechanical resonance that might damage the turbine.

However, fixed speed operation means that the maximum coefficient of performance $C_{\mathrm{p}}$ is available only at one particular wind speed. A lower coefficient of performance is observed for all other wind speeds, which reduces the energy output below that which might be expected from variable speed operation.

If the turbine speed could be adjusted in relation to the wind speed, then a higher average coefficient of performance and a higher average output could be realised. Variable pitch operation increases complexity and cost in conventional VAWT turbines, but if passive pitch control can be achieved in Crossflex it raises the possibility of a variable speed turbine operation. If the load can accept shaft power according to the max power curve in Fig. 13 the turbine will then operate at maximum power for any given wind speed, so the energy output will be maximised. If this maximum energy output can be obtained without increasing losses or costs, the system could extract more energy from the wind at a lower cost per unit of energy.

Variable speed operation requires a load which has a suitable curve of power input vs rotational speed. In examining various types of loads Johnson [27] established that the input power to pumps and fans often has a cubic variation with rotational speed. The power input to an electrical generator connected to a fixed resistance will vary as the square of the rotational speed. The power input to a generator used to charge batteries will vary even more rapidly than cubic. Load curves like the one shown in Fig. 13 are therefore quite possible, so variable speed operation is possible with several applications. Also, the use of power electronics and intelligent control systems could optimise the generator power demand in order to coincide with the rotor power for maximum aerodynamic efficiency.

Analysis of the turbine torque vs the load torque indicates that a variable speed turbine is technically possible. There is a possibility of simplified construction and lower costs and also a possibility of greater energy production from a given rotor. Fixed speed systems will probably dominate where induction or synchronous genera- 


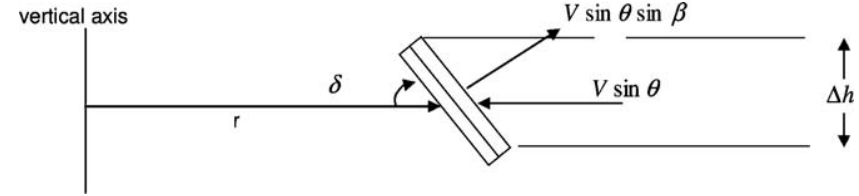

Fig. 10. Meridion angle $\mathrm{TM}^{\mathrm{TM}}$.

tors are used to supply power to the grid, but variable speed systems may find a role in stand-alone situations.

\subsection{Over-speed protection}

Although a generator with a suitable load characteristic can limit the rotor speed, a further limiting device is required should the generator either fail or provide insufficient counter torque in gusty conditions. Ideally this other speed limiting device will take the form of a passive mechanism which induces a greater pitch change at a specific rpm and so drastically reduces the aerodynamic performance of the blades in order to limit the rotor torque above that rpm.

However, pitching for purposes of limiting rotor speed is not nearly as simple in the case of a Darrieus VAWT compared to that of a conventional HAWT. With a Darrieus turbine it is important to note that the blade when adopting its natural troposkien shape will have a continually varying meridian angle, $\delta$, depending on position along the rotor axis, as shown in Fig. 10.

As such, the velocity vectors will be constantly changing with respect to the aerofoil chord, which ultimately translates to a continually varying angle of attack depending on position along the rotor axis (shown in Fig. 14 as the vertical axis). In addition, the angle of attack also changes with the azimuth angle, $\theta$. In other words for each rotation the angle of attack at any point on the blade will cycle between maximum and minimum values.

Initial analysis through a case study indicates a pitch angle of $+17.5^{\circ}$ results in an average rotor torque per rotation of $5.59 \mathrm{~N} \mathrm{~m}$. Since the zero pitch average torque per rotation was $13.15 \mathrm{Nm}$, a $+17.5^{\circ}$ pitch angle would lead to a drop off in rpm, in order to maintain balance between the generator counter torque and the mechanical torque of the rotor. This angle provides a combination of mainly pitching to stall (upwind) but also slight pitching towards feathering (downwind) produces the best result for limiting the speed of the turbine at $500 \mathrm{rpm}$.
However, with such a large pitch is likely to have effects on both rotor stability and power output. With the effect of $a+17.5^{\circ}$ pitch angle, the aggregate torque of all three blades combines to produce a considerably more sinusoidally varying output compared with the zero pitch case. Clearly, the rotor torque at zero pitch angle is more consistent for one full rotation, when compared to the same at $\mathrm{a}+17.5^{\circ}$ pitch angle, which features torque peaks at $90^{\circ}, 210^{\circ}$ and $330^{\circ}$. This "peaky" rotor torque behaviour at high pitch angles could prove to be problematic for the turbine stability. Hopefully, the structural integrity and the larger centrifugal forces would negate the effects of this peaky torque at high pitch angles. In addition, the turbine should be designed so that the passive pitch speed limiting device operates seldom; namely at very high wind conditions or in case of generator failure.

Possible models being examined include twisting of the blade, either through feathering or stalling. This will depend on the blade material and construction, and also the nature of the fixing at the blade root. The use of dampers at these points, either at one end or both ends, seems the most promising approach.

There may be an additional need for a release mechanism which would operate to provide aerodynamic limiting of the upper rotational speed should normal speed limiting measures fail.

Under certain conditions (a predefined threshold rotational speed) the release mechanism will release all blades simultaneously to avoid imbalance.

The mechanism for doing this could include (but not be limited to):

- Blade release clamp induced by tension force in the blade due to centripetal forces on the blade as it rotates. Calibration of this release clamp will be achieved using pre-stressed springs

- A loop of wire or chord of known breaking strength which restrains each blade by looping through a pin in the blade. If the rotational speed reaches over-speed condition then the loop breaks and all the blades are released from the slots.

The release mechanism will likely involve (but may not necessarily be limited to) the release of one end of the blades. The mechanism may therefore involve the partial release of one or both ends of the blades, whereupon the blade is only partially released from the hub to the extent that it deforms the troposkien shape but is still connected to the shaft via upwards or downwards movement on a rail.

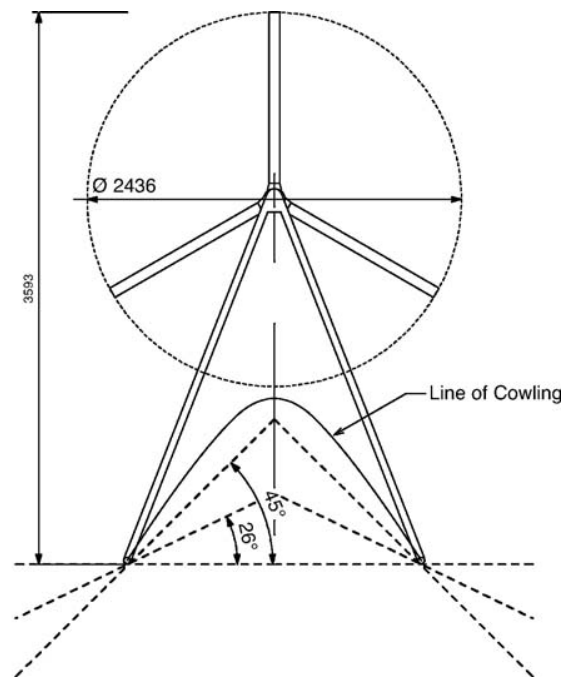

Fig. 11. Front and side elevations. 
The power density based on the streamtube analysis is promising, indicating a power output of up to $1 \mathrm{~kW}$ and a power density $0.196 \mathrm{~kW} / \mathrm{m}^{2}$. However, this analysis does not take into account induced velocities. Allowing for this but also modifying the toeout angle indicated a figure of $0.79 \mathrm{~kW}$, but work on ducted and augmented systems suggests that additional enhancements are possible through the form of the cowling.

\subsection{Building integration}

Most iterations of the Darrieus form have placed the turbine on a mast. The mast is cantilevered from the ground, which causes bending stresses on the shaft and requires a rigid foundation. When building mounted, this causes high ocalised loads on the building structure. A significant development of the Crossflex concept is the placement of the turbine within a cowling and the general arrangement is shown in Fig. 11.

There are a number of advantages to this.

1 The shaft is supported at either end and therefore is in simple bending. Consequently the loads on the fixings, shaft and bearings are significantly reduced and smaller and lighter elements can be used. In theory it may be possible to omit the shaft entirely and utilise the stiffness of the frame, both to support the bearings and blades, but also to contribute to passive pitch control mechanisms.

2 The cowling also provides a much greater range and spread of potential fixing points to the host structure. Not only does this spread the loads imposed onto the host structure, it also enables a degree of adaption to varying underlying forms. Thus fixing points can be positioned, within certain limits, to suit the structural system of the host structure. This is a critical aspect in relation to the application to existing buildings, in which the structure is varied, and generally cannot be altered. For example, a building with steel trusses at $2400 \mathrm{~mm}$ centres section may only require four fixing points on two trusses, but one with weaker timber trusses at $600 \mathrm{~mm}$ centres may accommodate up to ten fixings over five trusses. Fixings to solid substrates such as concrete or brickwork can be centres appropriate to the strength

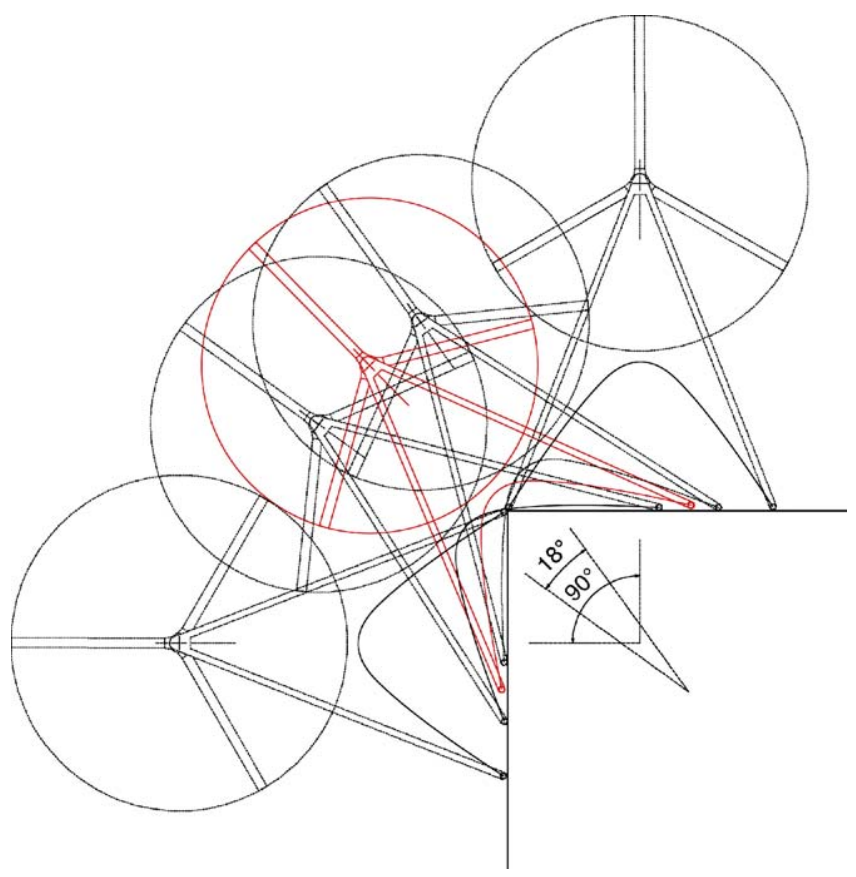

Fig. 12. Variable placement options. of the material. Overall weight of the turbine has not yet been estimated and will depend on the materials used to form the cowl. The structure also needs to be sufficient to accommodate vibration, particularly in respect of variable torques experienced during over-speed protection However, given the lightweight nature of the blades and cowl materials, overall loads will compare favourably with convential HAWT systems.

3 The form of the cowl has the potential to augment and concentrate airflow over the blades. One of the variable factors in the urban environment is the presence of turbulent airflows and vortex shedding of around buildings. As buildings are not generally designed to accommodate this, some adaption is necessary to help smooth airflow into the turbine path, and the benefits of this have been identified by Aguilo et al. [28] and Wang et al. [29]. Although not a fully ducted system, some improvement in airflow is anticipated. CFD analysis will be undertaken in subsequent stages of the development to optimise this.

To maximise the number of potential locations that may be exploited, and to enable variable positioning to exploit augmented airflows, the design of the cowl also allows considerable flexibility in the positioning of the turbine. Fig. 12 shows a variety of positions on a $90^{\circ}$ corner. This could be horizontal mounting on roof pitches from flat to $45^{\circ}$; horizontal mounting on parapet edges; or vertical mounting on building corners in plan.

This enables placement where concentration of wind occurs, for example, rising flow up vertical surfaces, or toward the prevailing wind direction on building corners or ridges. The turbine does not need to yaw to face wind direction, but some locations

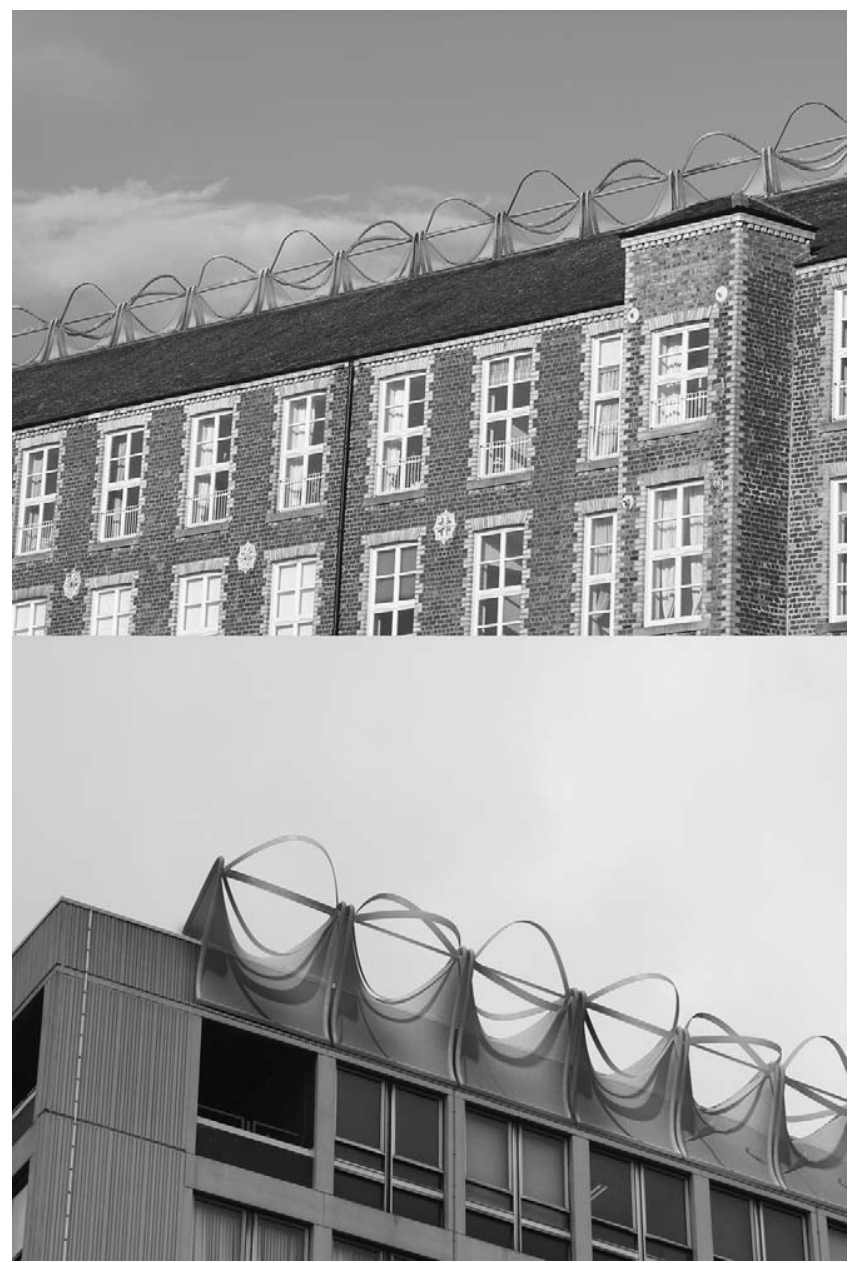

Fig. 13. Architectural integration parapet and ridge. 


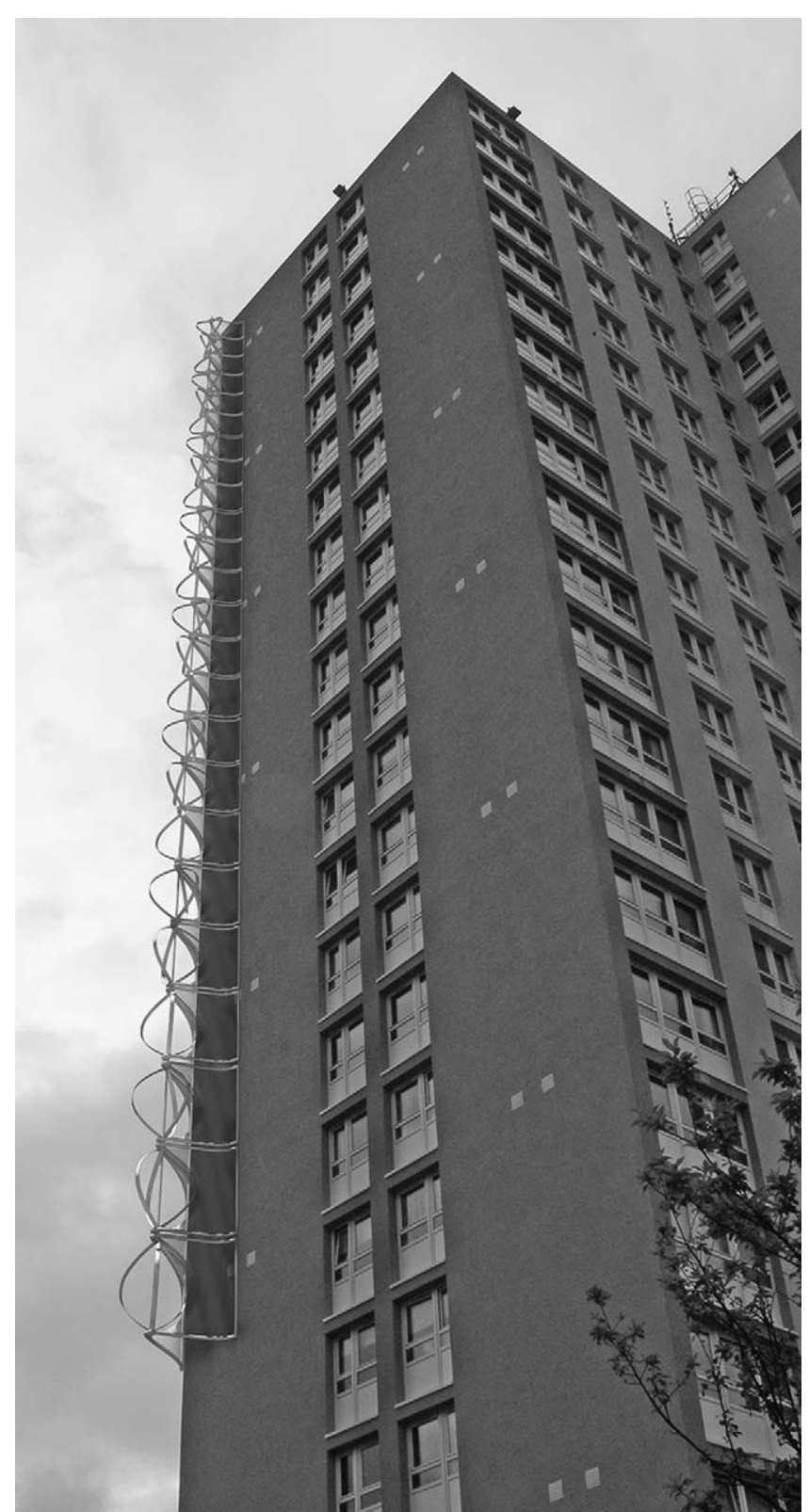

Fig. 14. Architectural integration corner.

will be subject to wind shadowing or lack access to prevailing winds on leeward sides, especially at edges, so siting must account to prevailing winds.

4 The cowl provides an interface with the host building to assist with visual integration and this is illustrated in Figs. 13 and 14 which show photomontages of placement on a range of building types and situations.

The cowl material has the potential to be varied with colour and to some degree texture to match building materials. There are a number of possible materials that may be used to form the cowl, the most obvious being composite materials such as glass or carbon reinforced plastics. This may provide the opportunity for the cowl to act as a monococque structure. However, the localised loads at the shaft connection may be difficult to accommodate, and issues of vibration would need to be analysed.

The alternative strategy would be to provide a steel structural frame, with a very lightweight skin. The required shape of the cowl naturally produces an anticlastic form and this allows the use fabrics and films. As well as being very lightweight, these can also potentially provide some degree of transparency may reduce its visual impact and aid visual integration, as well as being be easily replaceable.

The importance of visual appearance and integration should not be underestimated in this market. Whilst planning guidance [30] and more recent consultations on extensions of permitted development rights attempt to ease issues of planning permission, in many situations it will still be required. Furthermore, improved appearance, flexibility of installation and integration will enhance wider acceptance by architects and the public. This issue is particularly important with regard to installation on existing buildings.

A key aspect of the proposal is that of modularity. As previously discussed, conventional turbine development has attempted to provide efficiency and capacity though increased scale. In the built environment market there are limitations to the scale of turbine that can be accommodated both technically in terms of loads, and visually in terms of scale and integration.

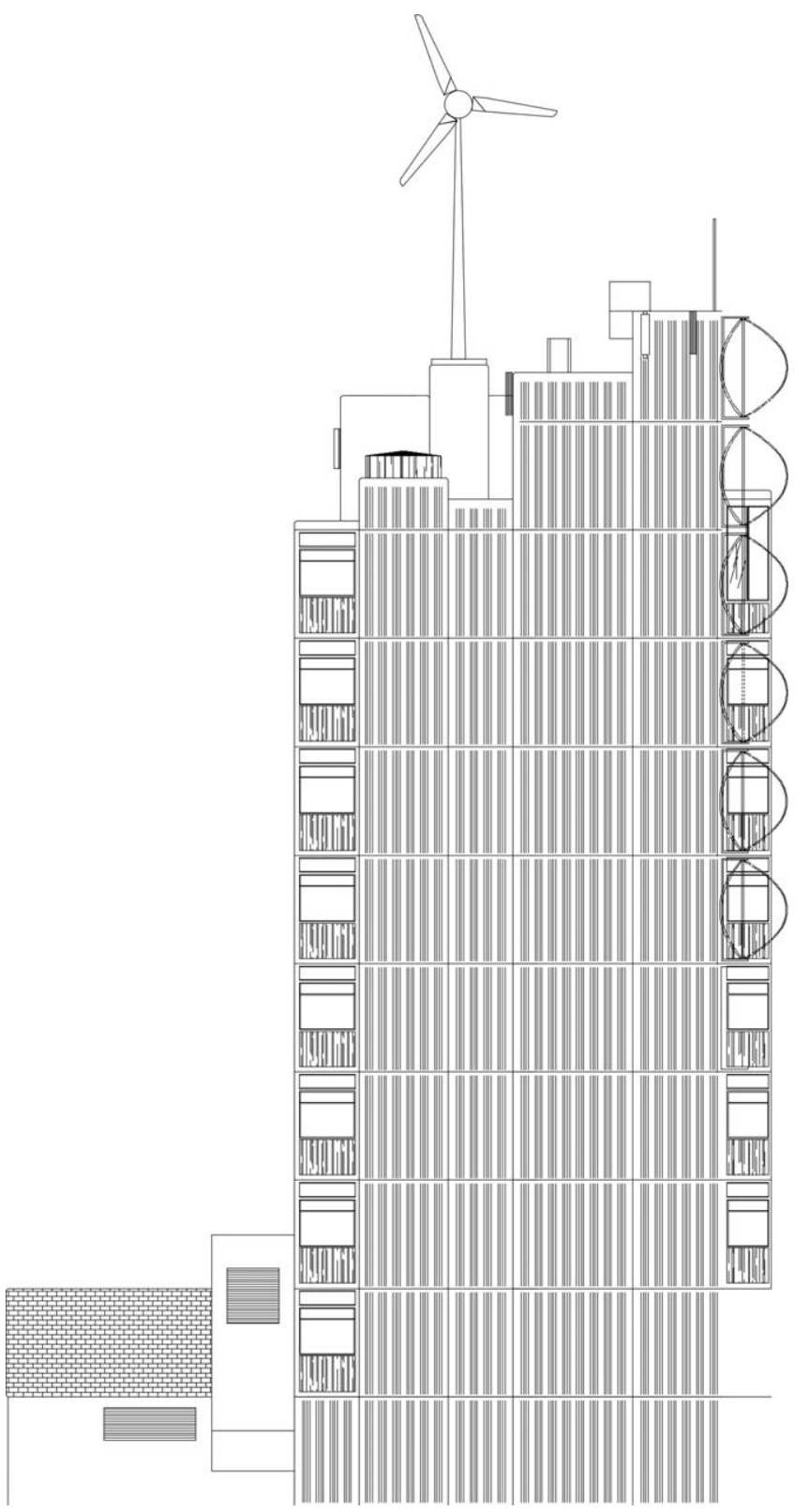

Fig. 15. $6 \mathrm{~kW}$ proven VAWT vs 6 No $1 \mathrm{~kW}$ Crossflex. 
The intention behind Crossflex is to produce a relatively small, but potentially modular device. Keeping the turbine small helps to minimise and distribute structural loads, reduces vibration to the host structure, and reduces the scale of plant required for installation.

A modular system can use a larger number of units can increase capacity. This is an especially important characteristic in relation to corner and edge mounting on tall buildings whereby installation capacity is significantly greater. This can be illustrated in Fig. 15, which shows a comparison of the visual impact of a $6 \mathrm{~kW}$ VAWT turbine with 6 Crossflex turbines on the Newbery Tower, a campus building at GSA.

The use of Crossflex provides a far more disbursed model and there are also fewer localised structural point loads. Although there are a larger number of fixings these will be taking much smaller loads, so can more rapidly installed bolt or anchor systems. In this example, installed capacity could be between a factor of 4 or 6 times greater if all possible mounting locations where used.

Modularity also leads to economies of scale derived from reduced manufacturing costs and generic fixing and installation systems. It enables interchangeable components for maintenance or change in appearance (for example material or colour or the cowl). Conventional building mounted installations have significant installation costs and technical difficulties, for example structural loads, and installing a larger number of units need not necessarily increase these. Indeed modularity can also assist with the feasibility of installation if components can be kept small enough to be easily handled and assembled in situ with the minimum of plant.

\section{Conclusions}

There is a rising demand for renewable energy technologies due to escalating targets for $\mathrm{CO}_{2}$ reduction, increasing fuel costs, and incentives such as feed in tarrifs. The small wind market has expanded rapidly, and whilst well-specified, well-sited turbines can make very useful contributions, there is an underlying concern that there has been a rush to market of conventional machines that are not sufficiently well adapted for use in urban environments.

The built environment market is more complex than rural installations, with a number of compound interactions involving human factors such as clients, specifiers, designers, the public, legislatory and statutory bodies, as well as technical issues such as turbulence, installation, safety and environmental impacts. It is therefore critical that devices for this market need to be designed with these factors in mind. The development of turbines that are visually attractive and capable of being integrated on both new and existing buildings increases this market.

This research offers tentative validation that the characteristics of Crossflex offer significant advantages over conventional Darrieus turbines in terms of performance and usability. It has demonstrated that variation in blade pitch can contribute to overall performance through balancing of torques, optimisation of rotor speed and over-speed protection. Furthermore, the inclusion of a cowling improves other characteristics, including structural performance, fixings, visual appearance and building integration.

However, further work is required to progress this design. Issues to overcome self-starting torques, and mechanisms to induce twist are critical. Additional work will be undertaken through design development and prototyping to develop and test blade-twisting mechanisms for passive speed control, some of which have been discussed here. Research will also be conducted to further examine the types of generators that may be appropriate to this system and test the ability to 'daisy-chain' multiple machines connected to larger single generators.
Subsequent stages will involve supplementary computer modelling using Computational Fluid Dynamic analysis to model airflow over the cowling to establish the nature of augmentation and flow stability that may occur, and to optimise the design in respect of these. This stage will also investigate materials that may be used for the cowling, in terms of both functional and aesthetic performance and also possible behaviour of the frame as a mechanism for inducing passive twist in the blades. These designs will be evaluated against common building types to test methods of fixing, loads distribution and integration under a variety of built form conditions. The goal will be to undertake full-size prototyping and empirical validation of the design through establishing measured performance and output.

\section{Acknowledgements}

The author would like to thank Proven Energy for their assistance with the preparation of this paper, in particular Scott Love who worked on the early SMART funded stages, and Jonathan Nowill who provided valuable feedback on the paper.

\section{References}

[1] http://www.decc.gov.uk/en/content/cms/legislation/en/content/cms/ legislation/cc_act_08/cc_act_08.aspx.

[2] http://www.scotland.gov.uk/Topics/Environment/climatechange/scotlandsaction/climatechangeact

[3] B. Boardman, Home Truths: A low Carbon Strategy to reduce UK Housing emissions by $80 \%$ by 2050 , University of Oxford, 2007, ISBN 1874370435 , http:// www.eci.ox.ac.uk/research/energy/downloads/boardman07-hometruths.pdf.

[4] The Carbon Trust 2008 Low Carbon Refurbishment of Buildings, Management guide CTV038.

[5] A.S. Bahaj, L. Myers, P.A.B. James, Urban energy generation: influence of microwind turbine output on electricity consumption in buildings, Energy and Buildings 39 (February (2)) (2007) 154-165 (ISSN 0378-7788).

[6] DTI 2005, DTI, Potential for Microgeneration: Study and Analysis, Department of Trade and Industry, November 2005, http://www.berr.gov. uk/files/file27576.pdf.

[7] Boyack, The Energy Efficiency and Micro-Generation Bill Proposal 2005 http://www.scottish.parliament.uk/business/bills/pdfs/mbconsultations/ microgeneration.pdf.

[8] http://www.decc.gov.uk/en/content/cms/consultations/elec_financial/elec_ financial.aspx.

[9] Written Ministerial Statements, Thursday 8 June 2006, Communities and Local Government, PPS22.

[10] S. Mertens, Wind description for roof location of wind turbines; a design guideline or the required height of a wind turbine on a horizontal roof of a mid- to high-rise building, Global Windpower, Paris, France, 2-5 April, 2002 (Fig. 5, 20).

[11] S. Mertens, The wind conditions at flat roofs for small wind turbines, EWEC 2003, Madrid, Spain, 16-19 June, 2003.

[12] D. Taylor, Using buildings to harvest wind energy, Building Research and Information 26 (May (3)) (1998) 199-202.

[13] N.S. Campbell, S. Stankovic, Wind energy for the Built environment-Project WEB, A report for Joule III Contract No JOR3-CT98-01270 2001.

[14] K. Steemers, et al., Project ZED, Modelling environmental characteristics of urban forms, Solar Energy in Architecture and Urban Planning, H.S. Stephens, Bedford, pp. 4-7,1996.

[15] L. Lu, K.Y. Ip, Investigation on the feasibility and enhancement methods of wind power utilization in high- rise buildings of Hong Kong, Renewable and Sustainable Energy Reviews (2008) 01, doi:10.1016/j.rser.2007.11.

[16] S.J. Watson, D.G. Infield, J.P. Barton, S.J. Wylie, Modelling of the performance of a building-mounted ducted wind turbine, Journal of Physics: Conference Series 75 (2007) 012001, doi:10.1088/1742-6596/75/1/012001.

[17] R.K.W. Dannecker, A.D. Grant, Investigations of a building-integrated ducted wind turbine module, Wind Energy 5 (1) (2002) 53-71.

[18] A.D. Peacock, D. Jenkins, M. Ahadzi, A. Berry, S. Turan, Micro wind turbines in the UK domestic sector, Energy and Buildings 40 (7) (2008) 1324-1333 (ISSN 0378-7788).

[19] The Carbon Trust, Small-scale wind energy policy insights and practica guidance, August 2008, http://www.warwickwindtrials.org.uk, interim report, 2008.

[20] Nalanie Mithraratne, Roof-top wind turbines for microgeneration in urban houses in New Zealand, Energy and Buildings 41 (October (10)) (2009) 1013-1018 (ISSN 0378-7788).

[21] www.swiftwindturbine.com.

[22] www.quietrevolution.co.uk.

[23] www.turby.nl 
[24] T. Sharpe, Building mounted wind turbines on existing multi-storey housing, Open House International (September) (2008) 0168-2601.

[25] J.H. Strickland, The Darrieus Turbine: A Performance Prediction Model Using Multiple Streamtubes, Sandia Laboratories Energy Report, 1975.

[26] I. Paraschivoiu, Wind Turbine Design With Emphasis On Darrieus Concept, Polytechnic International Press, 2002.

[27] G.L. Johnson, Wind Energy Systems 2001 available at http://eece.ksu.edu/ gjohnson/.
[28] A. Aguilo, D. Taylor, A. Quinn, R. Wiltshire, Computational fluid dynamic modelling of wind speed enhancement through a building augmented wind concentration system, European Wind Energy Conference, 2004.

[29] F. Wang, L. Bai, J. Fletcher, J. Whiteford, D. Cullen, Development of small domestic wind turbine with scoop and prediction of its annual power output, Renewable Energy 33 (July (7)) (2008) 1637-1651.

[30] Planning for Micro Renewables Annex to PAN 45 Renewable Energy Technologies http://www.scotland.gov.uk/Publications/2006/10/03093936/0. 